\title{
A Three-layer diffusion-cell to examine bio- enhanced dissolution of chloroethene dense non-aqueous phase liquid
}

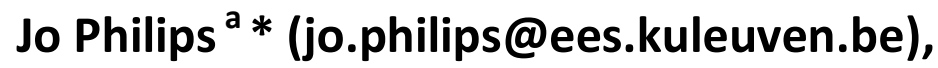 \\ Dirk Springael a (dirk.springael@ees.kuleuven.be) \\ \& Erik Smolders ${ }^{a}$ (erik.smolders@ees.kuleuven.be) \\ ${ }^{a}$ Division of Soil and Water Management, KU Leuven (University of Leuven), \\ Kasteelpark Arenberg 20, B-3001 Heverlee BELGIUM, \\ Tel: +3216321609 Fax: +3216321997 \\ * Corresponding author
}

\begin{abstract}
Microbial reductive dechlorination of trichloroethene (TCE) and perchloroethene (PCE) in the vicinity of their dense non-aqueous phase liquid (DNAPL) has been shown to accelerate DNAPL dissolution. A three-layer diffusion-cell was developed to quantify this bio-enhanced dissolution and to measure the conditions near the DNAPL interface. The $12 \mathrm{~cm}$ long diffusion-cell setup consists of a $5.5 \mathrm{~cm}$ central porous layer (sand), a lower $3.5 \mathrm{~cm}$ DNAPL layer and a top $3 \mathrm{~cm}$ water layer. The water layer is frequently refreshed to remove chloroethenes at the upper boundary of the porous layer, while the DNAPL layer maintains the saturated chloroethene concentration at the lower boundary. Two abiotic and two biotic diffusion-cells with TCE DNAPL were tested. In the abiotic diffusion-cells, a linear steady state TCE concentration profile between the DNAPL and the water layer developed beyond 21 days. In the biotic diffusion-cells, TCE was completely converted into cis-dichloroethene (cis-DCE) at $2.5 \mathrm{~cm}$ distance of the DNAPL. Dechlorination was likely inhibited up to a distance of $1.5 \mathrm{~cm}$ from the DNAPL, as in this part the TCE concentration exceeded the culture's maximum tolerable concentration $(2.5 \mathrm{mM})$. The DNAPL dissolution fluxes were calculated from the TCE concentration gradient, measured at the interface of the DNAPL layer and the porous layer. Biotic fluxes were a factor 2.4 (standard deviation 0.2) larger than abiotic dissolution fluxes. This diffusion-cell setup can be used to study the factors affecting the bio-enhanced dissolution of DNAPL and to assess bioaugmentation, $\mathrm{pH}$ buffer addition and donor delivery strategies for source zones.
\end{abstract}

KEYWORDS

TCE, DNAPL, diffusion-cell, bio-enhanced dissolution, reductive dechlorination, biodegradation 


\section{INTRODUCTION}

Trichloroethene (TCE) and perchloroethene (PCE) are widespread groundwater pollutants, which form dense non-aqueous phase liquids (DNAPL). Bioremediation through reductive dechlorination by halorespiring bacteria is commonly applied on the contaminant plumes. However, bioremediation in the source zone, i.e. the zone with DNAPL, could be more effective, as dechlorination in the vicinity of the DNAPL can increase the concentration gradient and, as such, enhance the DNAPL dissolution rate and reduce the remediation time (Yang and McCarty, 2000). Bio-enhanced dissolution of PCE DNAPL has been demonstrated with enhancement factors compared to abiotic dissolution ranging between 1.5 and 21 (Amos et al., 2009). Different factors are likely to control this bio-enhanced dissolution. For instance, the dissolution enhancement is probably limited by self-inhibition, i.e., inhibition of the dechlorination at elevated PCE and TCE concentrations (Amos et al., 2007; Duhamel et al., 2002). Electron donor requirements and $\mathrm{pH}$ constraints are other potential limiting factors (McCarty et al., 2007). In addition, insufficient activity of dechlorinating bacteria can limit the DNAPL dissolution enhancement (Barnes et al., 2010; Da Silva et al., 2006; Schaefer et al., 2010). Therefore, the effect of abiotic and biotic factors on the dissolution enhancement should be known to correctly estimate the bioenhanced dissolution. These effects can only be elucidated by a quantification of the dissolution enhancement in combination with the measurement of abiotic and biotic conditions in the vicinity of the DNAPL.

Bench-scale tests studying bio-enhanced dissolution have used a variety of setups, including batch reactors (Adamson et al., 2004; Amos et al., 2007), 1-D columns (Amos et al., 2008, 2009; Cope and Hughes, 2001; Yang and McCarty, 2000, 2002), stirred tank reactors (Carr et al., 2000), flow cells (Glover et al., 2007), 2-D tanks (Da Silva et al., 2006; Sleep et al., 2006) and a 3-D tank (Adamson et al.,
2003). Batch reactors are the easiest to handle, but disregard the diffusive and convective transport processes in aquifer systems. Column (1-D) tests include these transport processes, but consist of a flow through rather than in a flow along the DNAPL. Setups like 2-D and 3-D tanks most realistically simulate contaminated aquifers, but are complex to handle and difficult to reproduce. In addition, the estimation of the dissolution enhancement in 1-D columns and in 2-D and 3-D tanks is based on the effluent composition, leaving aside the processes acting at the interface of the DNAPL. We developed a new bench-scale setup to reproducibly quantify the bio-enhanced dissolution of DNAPL and to measure the conditions near the DNAPL interface. This new setup consists of a three-layer diffusion-cell. The three layers are a central sand layer, a lower DNAPL layer and a top water layer (Figure 1). The water layer is frequently refreshed to act as a zero sink for the chloroethenes and to provide electron donor at the upper boundary of the central layer. The DNAPL layer maintains the saturated chloroethene concentration at the lower boundary. These boundary conditions result in concentration gradients which induce diffusion of the chloroethenes and the electron donor in opposite direction through the porous layer. This paper describes the technical aspects of the diffusion-cell setup and the results of an experiment with abiotic and biotic diffusioncells containing TCE DNAPL.

\section{MATERIAL AND METHODS}

\subsection{Diffusion-cell setup}

Diffusion-cells are set up in glass cylinders of 12 $\mathrm{cm}$ length and $3.3 \mathrm{~cm}$ internal diameter (Figure 1). Screw lids with Viton liners close both cylinder ends. Each cylinder is provided with 12 sampling arms of $3 \mathrm{~mm}$ internal diameter spaced about $5 \mathrm{~mm}$ from each other. Each sampling arm is sealed with a screw cap with Viton septum. Glass wool in the sampling arms prevents their blockage. 


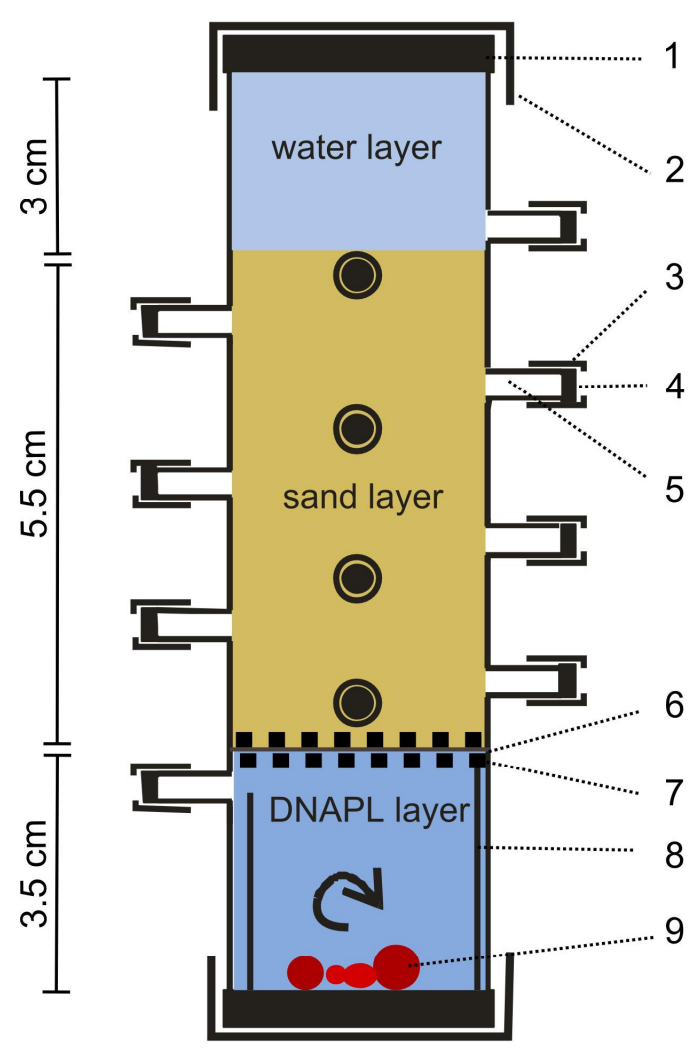

A.

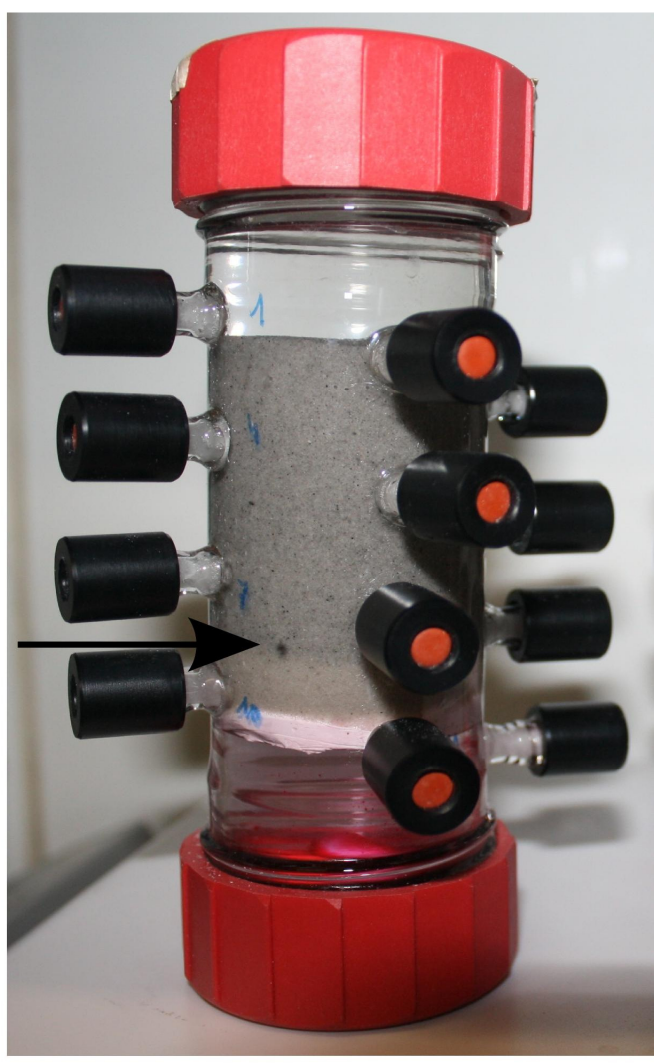

B.

Figure 1: Technical scheme (A) and picture (B) of the diffusion-cell setup. In A is 1) Viton liner, 2) screw lid, 3) screw cap, 4) Viton septum, 5) glass wool, 6) glass fiber membrane, 7) glass grid, 8) glass ring with opening at lower sampling port and 9) pure TCE droplets. The arrow in B shows the change in substrate color. Additional details are given in the text.

Diffusion-cells are made up of three layers, i.e. a central sand layer with a water layer on top and a DNAPL layer underneath. The central layer consists of fine grained sand and is about $5.5 \mathrm{~cm}$ thick. This sand layer can be inoculated with a dechlorinating culture. On top is the water layer with a thickness of $3 \mathrm{~cm}$. This layer is frequently refreshed. The DNAPL layer is 3.5 $\mathrm{cm}$ thick and consists of an aqueous solution with pure TCE droplets stained with $0.5 \mathrm{~g} \mathrm{~L}^{-1}$ Oil-Red-O. Saturation of TCE in this layer is attained by continuous stirring with a magnetic stir bar. The aqueous solution of the DNAPL layer is contained in a glass ring of $3 \mathrm{~cm}$ height and $2.8 \mathrm{~cm}$ internal diameter. This ring carries a double glass grid of $5 \mathrm{~mm}$ thickness, which supports the central sand layer. A $0.8 \mu \mathrm{m}$ pore size glass fiber membrane in between the two grids prevents sand particles from falling through the grid. The edge of the double grid is wrapped with Teflon tape to obtain a close fit with the inside of the cylinder to avoid sand particles falling over the grid edge.

Water and pore water samples of the diffusioncells are taken with a syringe. Before every sampling, $0.5 \mathrm{~mL}$ sterile nitrogen gas is injected through the upper sampling port to obtain a small overpressure in the cell. Subsequently, $0.3 \mathrm{~mL}$ samples of the aqueous solution or the pore water are taken. The overpressure avoids air bubbles to enter upon removal of the needle.

At the end of an experiment, the diffusion cells are destructively sampled. A plunger holding a 
$3.3 \mathrm{~cm}$ diameter Teflon disc is pushed through the cylinders by ticking with a small hammer. The protruding sand is sliced in about $5 \mathrm{~mm}$ thin layers. The exact thickness of the sand slices is measured with a digital caliper. Initially, a screw plunger was tried to move the disc, but this plunger got blocked as the sand really stuck in the cylinders.

In the initial designs of the diffusion-cell setup the DNAPL layer was a sand layer saturated with TCE. This type of DNAPL layer was not used further since the DNAPL migrated out. First, it was found that water pored on TCE saturated sand displaces the DNAPL, likely because of the better wetting of the sand by the water. Therefore, a second setup was tried in which the TCE saturated sand was put on top of the water saturated sand. After filling, these diffusion-cells were turned upside-down and the top part of the sand layer was removed to establish the water layer. This way of filling resulted in a visibly clear separation between the DNAPL and the central layer. However, during incubation the DNAPL moved upwards in several replicates. In some diffusion-cells the DNAPL even accumulated in the lower sampling ports. This DNAPL mobilization obviously obscured the diffusive gradients, and therefore, the design of the diffusion-cells was modified. In the final diffusion-cell setup (Figure 1) the DNAPL layer, consisting of an aqueous solution with DNAPL droplets, prevents migration of the DNAPL. Direct contact between the DNAPL and the sand layer is avoided by a membrane filter and by the TCE droplets remaining at the bottom of the solution.

\subsection{Diffusion-cell experiment}

To test the diffusion-cell setup, an experiment with two abiotic ( $A B I O 1$ and $A B I O 2)$ and two biotic diffusion-cells (BIO1 and $\mathrm{BIO} 2$ ) was performed. Biotic diffusion-cells were inoculated with the dechlorinating culture described below and had formate as electron donor in their top water layer. Abiotic diffusioncells were filled aerobic, while biotic diffusioncells were filled in a glovebox with $\mathrm{N}_{2} / \mathrm{H}_{2}(95 / 5)$ atmosphere. Deionised water or anaerobic mineral medium, inoculated with $5.9 \%$ of the dechlorinating culture, were used to fill the abiotic or biotic diffusion-cells respectively. The composition of the anaerobic mineral medium is described by Haest et al. (2011), it contained $30 \mathrm{mM}$ MOPS $\left(\mathrm{pK}_{\mathrm{a}}=7.2\right)$ and $15 \mathrm{mM}$ hydroxide as $\mathrm{pH}$ buffer. Fine quartz sand (type M34, mean diameter $170 \mu \mathrm{m}, 0.0 \%$ organic matter) provided by Sibelco (Mol, Belgium) was used as porous material. The resulting packing had a volumetric moisture content of $38 \%$, determined by analysis of dry and wet weight. The sand layer contained about $18 \mathrm{~mL}$ aqueous phase. The DNAPL layers contained $1 \mathrm{~mL}$ of TCE in about $18 \mathrm{~mL}$ of the solution used for packing. The $25 \mathrm{~mL}$ top layer consisted of deionised water in the abiotic diffusion-cells and anaerobic mineral medium with the addition of $4 \mathrm{mM}$ formate in the biotic diffusion-cells. All diffusion-cells were incubated at $20 \pm 1^{\circ} \mathrm{C}$. Top water layers were refreshed twice a week and were every time sampled. The pore water of the abiotic diffusion-cells was sampled for analysis of the chloroethenes on day $7,14,21$, 28 and 41 . Pore water samples of the biotic diffusion-cells were taken for chloroethene analysis on day 18, 25 and 32 and for formate analysis on day 21 . At day 35 , the sand layers of the biotic cells were sliced and sampled for $\mathrm{pH}$ measurements.

\subsection{Used culture}

The KB- $1^{\mathrm{TM}}$-culture was provided by SiREM (Ontario, Canada). A subculture was grown in anaerobic mineral medium (Haest et al., 2011) on $1.6 \mathrm{mM}$ TCE and an equimolar amount of formate. To stimulate only the conversion of TCE to cis-DCE, the aqueous phase was flushed with $\mathrm{N}_{2}$ and respiked with the same amounts of TCE and formate after cis-DCE was formed. Geobacter was the dominant dechlorinating species in this culture and formed about $10 \%$ of the total cell number. Low numbers of Dehalococcoides were present and the culture only showed cis-DCE reduction after extended exposure to cis-DCE (results not shown). A 
preliminary batch degradation experiment showed TCE dechlorination by this culture up to $2.5 \mathrm{mM}$ TCE, above this concentration no dechlorination was observed (results not shown). This concentration is higher than the maximum tolerable TCE concentration of the $\mathrm{KB}-1^{\mathrm{TM}}$-culture reported by Duhamel et al. (2002) (1.5 mM), perhaps because of the enrichment of Geobacter or the acclimatization to high TCE concentrations in our culture. As electron donor formate was chosen for this culture because of its good $\mathrm{pH}$ buffering capacity (McCarty et al., 2007).

\subsection{Analytical methods}

TCE, cis-DCE and methane concentrations were measured by GC-FID headspace analysis, as described by Haest et al. (2010), with detection limits respectively of $0.006 \mathrm{mM}, 0.011 \mathrm{mM}$ and $0.006 \mathrm{mM}$. Formate and acetate concentrations were measured by means of ion exclusion chromatography with a Dionex ICE AS- 6 column and AMMS ICE-II suppressor. Detection limits of $0.11 \mathrm{mM}$ and $0.28 \mathrm{mM}$ were obtained respectively for formate and acetate. Sand samples were suspended in $0.01 \mathrm{M} \mathrm{CaCl}_{2}$ solution before $\mathrm{pH}$ measurement with a Metrohm Platina electrode.

\section{RESULTS}

\subsection{Abiotic diffusion-cells}

Pore water TCE concentration profiles were linear in both abiotic diffusion-cells from day 21 onwards (Figure 2A). Concentrations of TCE decreased from approximately $8 \mathrm{mM}$, i.e. the saturated TCE concentration, in the DNAPL layer, to below detection in the upper water layer. After day 21, concentration profiles remained unchanged, indicating that the linear concentration profile was the steady state profile. The 1-D diffusive process in the diffusion-cells is described by equation (1):

$$
\frac{\partial c_{T C E, w}}{\partial t}=\xi \cdot D_{0} \cdot \frac{\partial^{2} c_{T C E, w}}{\partial z^{2}}
$$

where $C_{T C E, w}$ is the TCE concentration in the pore water, $t$ is time, $\xi$ is a tortuosity factor, $z$ is the distance from the DNAPL and $D_{0}$ is the diffusion coefficient for TCE in pure water. At steady state and with the boundary conditions imposed by the diffusion-cell setup, equation (1) yields the linear profile described by equation (2):

$$
c_{T C E, w}=-\frac{c_{T C E, s a t}}{z_{0}} \cdot z+c_{T C E, s a t}
$$

where $c_{T C E, \text { sat }}$ is the saturated TCE concentration and $z_{0}$ is the thickness of the central sand layer. The observed linear steady state concentration profile, therefore, confirms that the experimental setup was able to impose the conceptual boundary conditions.

Concentration profiles measured at day 7 and 14 were not linear (Figure 3 ). These transient concentration profiles were used to determine the effective diffusion coefficient of TCE in the sand layer, which is $\xi . D_{0}$ in equation (1). Therefore, the analytical solution (3) of transport equation (1) was adapted from the equation of Crank (1986) for diffusion through a plane sheet with uniform initial concentration and with constant concentrations at the boundaries.

$$
\begin{aligned}
& c_{T C E, w}=c_{T C E, s a t} \cdot\left(1-\frac{z}{z_{0}}\right) \\
& +\frac{2}{\pi} \cdot \sum_{n=1}^{\infty}\left(-\frac{c_{T C E, s a t}}{n} \cdot \sin \left(\frac{n \cdot \pi \cdot z}{z_{0}}\right) \cdot e^{\frac{-\xi \cdot D_{0} \pi^{2} n^{2}}{z_{0}^{2}} \cdot t}\right)
\end{aligned}
$$

This equation was fitted on the experimental data ( $R^{2}$ of 0.98 ) (Figure 3 ). Optimization was performed by least square difference minimization with Microsoft Excel Solver, while the macro SolverAid of Macrobundle was used to calculate the standard deviation. The resulting estimate for the effective TCE diffusion coefficient $\left(\xi . D_{0}\right)$ in the sand layer is $0.51 \pm 0.04 \mathrm{~cm}^{2} \mathrm{~d}^{-1}$.

Moldrup et al. (2000) developed a relationship for predicting the gaseous tortuosity factor from the porosity of structureless, repacked natural soils. The same relationship can be used for liquid tortuosity (Jury and Horton, 2004). Equation (4) adapts this relationship for 
saturated media, assuming that the volumetric moisture content $\vartheta$ equals the porosity:

$$
\xi=\theta^{1 / 2}
$$

The diffusion coefficient for TCE in water $\left(D_{0}\right)$ is $0.82 \mathrm{~cm}^{2} \mathrm{~d}^{-1}$ (Gulliver, 2007). At a volumetric moisture content of the sand $(\vartheta)$ of 0.38 , an effective diffusion coefficient $\left(\xi . D_{0}\right)$ of $0.51 \mathrm{~cm}^{2}$ $\mathrm{d}^{-1}$ can be calculated with equation (4), which is in perfect agreement with our experimentally derived value.

\subsection{Biotic diffusion-cells}

Pore water concentrations of TCE and cis-DCE in the biotic diffusion-cells were measured three times (at day 18, 25 and 32). Concentration profiles were similar at all times, indicating that a steady state profile was already attained before the first measurement (Figure 2B). A clearly steeper TCE concentration profile was found compared to the abiotic diffusion-cells. The TCE concentrations decreased from the saturated TCE concentration at the DNAPL layer to a zero concentration at $2.5 \mathrm{~cm}$ distance from the DNAPL, as a result of the biotic conversion to cis-DCE. The culture used was shown to dechlorinate TCE up to a concentration of 2.5 $\mathrm{mM}$ in liquid batch cultures (data not shown). Therefore, dechlorination was likely inhibited in the sand layer between 0 and $1.5 \mathrm{~cm}$ distance from the DNAPL, as in this part the TCE concentrations exceeded this concentration. As such, the TCE dissolving from the DNAPL was only degraded in the part of the sand layer, situated between 1.5 and $2.5 \mathrm{~cm}$ of the DNAPL layer. The cis-DCE concentration profile also reflects that the largest dechlorinating activity was situated at about $2 \mathrm{~cm}$ above the DNAPL, as the cis-DCE concentration had a maximum of approximately $4 \mathrm{mM}$ at this distance. The cisDCE concentration in the sand layer is maximal where cis-DCE is produced. From this point it diffuses to both boundaries since they both maintain zero-sink conditions for cis-DCE. This is because the top water layer is frequently refreshed and cis-DCE partitions in the TCE
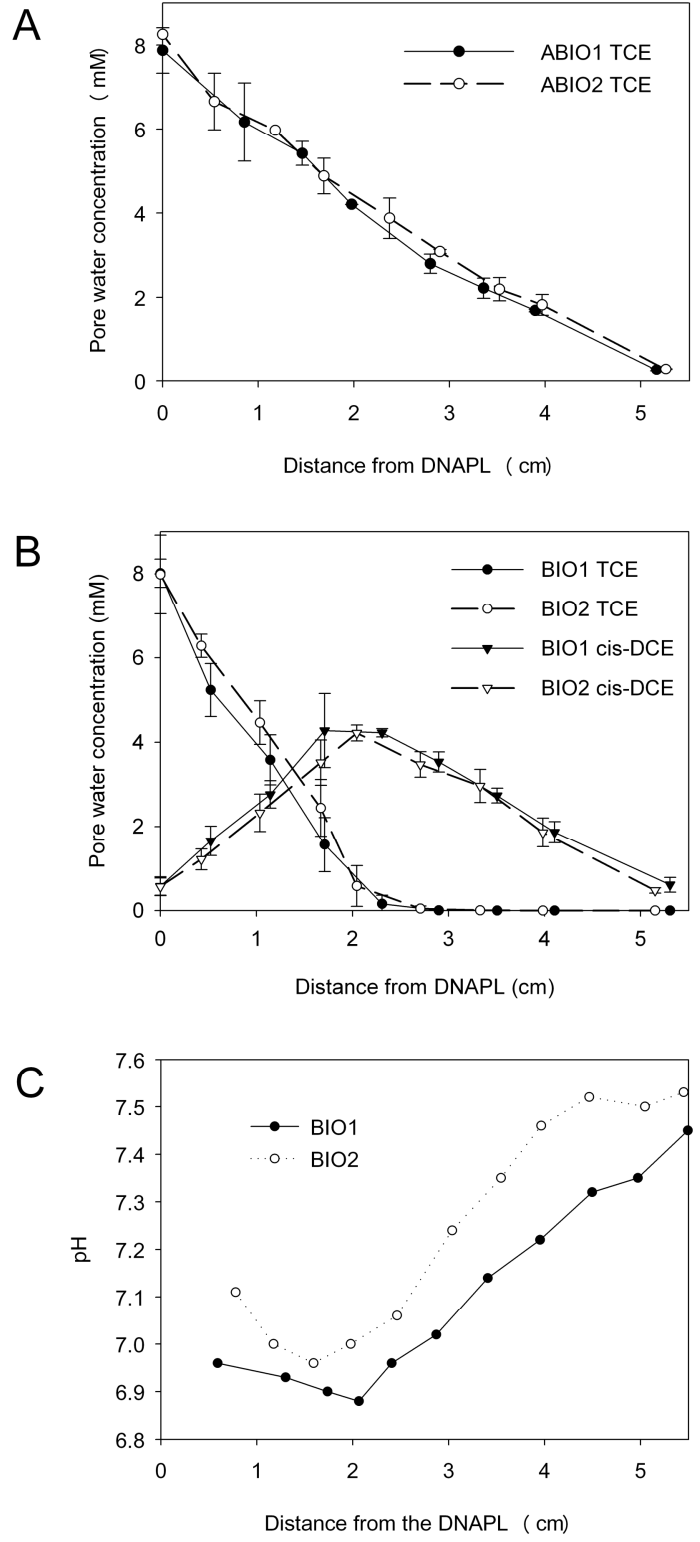

Figure 2: The chloroethene pore water concentrations in the abiotic diffusion-cells (A) and in the biotic diffusion-cells (B) and the pore water $\mathrm{pH}$ in the biotic diffusion-cells $(C)$ in relation to the distance from the DNAPL. The plotted concentrations are the averages of the concentrations measured at day 28 and 41 for the abiotic diffusion-cells and measured at day 18, 25 and 32 for the biotic diffusion-cells. The error bars give the standard deviation. The $\mathrm{pH}$ was measured on the sand samples destructively sampled at the end of the experiment. 


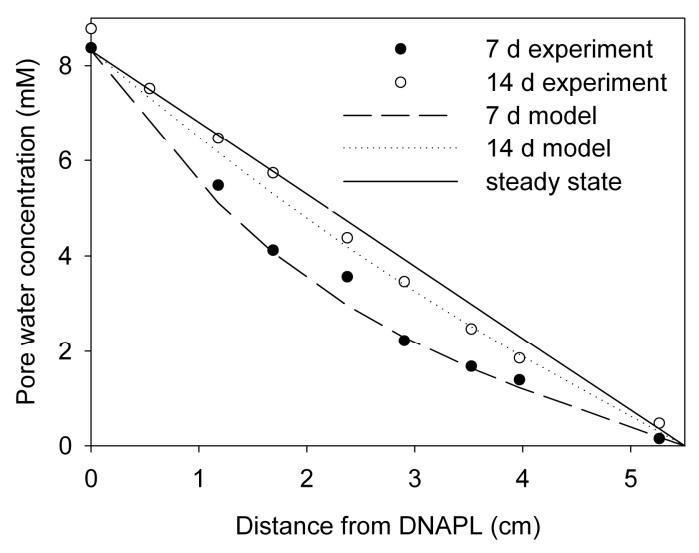

Figure 3: Measured and modeled pore water concentrations in relation to the distance of the DNAPL for $\mathrm{ABIO2}$ at day 7 and 14. Transient concentration profiles of both abiotic diffusion-cells were used to estimate the effective TCE diffusion

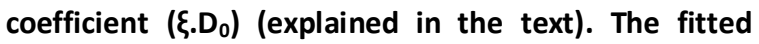
value was used in equation (3) to calculate modeled pore water concentrations. The linear steady state concentration profile is given for comparison.

DNAPL. Analysis of the microbial numbers was not performed, but could also give information about the location of the dechlorination in the sand layer.

The sand layer of both biotic diffusion-cells became grayish shortly after the start of the experiment, but the lowest centimeter remained light in color (Figure 1B). The darkening can be attributed to Fe(III) reduction, as the sand contained $0.5 \mathrm{mg}$ Fe per g dry sand as $\mathrm{Fe}$ (III) oxides. Iron becomes biologically reduced in anoxic conditions, which can lead to the formation of a black precipitation (e.g. mackinawite or magnetite) (Fredrickson et al., 1998; McCormick et al., 2002). As elevated TCE concentrations inhibit the dechlorination, they probably also inhibit other microbial processes, potentially explaining the lack of darkening in the lowest part of the sand layer.

Formate concentrations in the pore water of both biotic diffusion-cells were measured on day 21, but no formate was detected throughout the sand layer. The top water layer before refreshment contained some residual formate $(1-1.5 \mathrm{mM})$ in the initial week, but at later refreshments no formate was detected (results not shown). These findings could reflect electron donor limitations. In addition to the limited Fe(III) reduction, there was evidence for competitive reactions, as methane and acetate (respectively till $0.5 \mathrm{mM}$ and $3.0 \mathrm{mM}$ ) were measured in the biotic diffusion-cells (results not shown). However, TCE degradation was located rather far $(3.5 \mathrm{~cm})$ from the upper water layer and therefore did not reflect electron donor limitations, as in donor limiting conditions most electrons would be available at the interface with the top water layer. A likely explanation for the zero formate concentrations is the quick conversion of formate to $\mathrm{H}_{2}$, which would subsequently diffuse through the sand layer and provide the dechlorination with electrons. Concentrations of $\mathrm{H}_{2}$ in the diffusion cells were not measured.

At the end of the experiment, the $\mathrm{pH}$ was measured on sand samples (Figure $2 \mathrm{C}$ ). The lowest $\mathrm{pH}(6.93 \pm 0.04)$ was measured in the samples originating from 1.5 to $2 \mathrm{~cm}$ distance from the DNAPL. Beyond this distance, the $\mathrm{pH}$ clearly increased with increasing distance from the DNAPL to a value of $7.49 \pm 0.06$ at the top of the sand layer. Dechlorination is an acidifying reaction and, therefore, these $\mathrm{pH}$ data again indicate that maximum dechlorination was located at about $2 \mathrm{~cm}$ distance from the DNAPL. In addition, the increased $\mathrm{pH}$ in comparison to the $\mathrm{pH}$ of the medium (7.2) at the top of the sand layer suggests that formate was converted there, because the conversion of formate to $\mathrm{H}_{2}$ and $\mathrm{HCO}_{3}{ }^{-}$increases the $\mathrm{pH}$. Alternatively, the increased $\mathrm{pH}$ could be due to competitive reactions like methanogenenis and acetogenesis at the top of the sand layer.

\subsection{Calculation and comparison of biotic and abiotic DNAPL dissolution}

The DNAPL dissolution rate is determined as the flux of TCE dissolving out of the DNAPL. In the diffusion-cells this is the TCE flux through the interface of the DNAPL and the sand layer. 


\begin{tabular}{cccc}
\hline & $\begin{array}{c}\text { Concentration } \\
\text { Gradient } \\
\left(\mathrm{mM} \mathrm{cm}^{-1}\right)\end{array}$ & $\begin{array}{c}\text { Steady State } \\
\text { Dissolution Flux } \\
\left(\mu \mathrm{mol} \mathrm{d}^{-1} \mathrm{~cm}^{-2}\right)\end{array}$ & $\begin{array}{c}\text { Time Averaged } \\
\text { Dissolution Flux } \\
\left(\mu \mathrm{mol} \mathrm{d}^{-1} \mathrm{~cm}^{-2}\right)\end{array}$ \\
\hline ABIO theoretical & 1.45 & 0.28 & \\
$\mathrm{ABIO1}$ & $1.48 \pm 0.07$ & $0.29 \pm 0.03$ & 0.32 \\
$\mathrm{ABIO2}$ & $1.44 \pm 0.06$ & $0.28 \pm 0.02$ & 0.36 \\
$\mathrm{BIO1}$ & $3.64 \pm 0.28$ & $0.71 \pm 0.08$ & 0.66 \\
$\mathrm{BIO2}$ & $3.27 \pm 0.27$ & $0.63 \pm 0.07$ & 0.68 \\
\hline
\end{tabular}

Table 1: Comparison of abiotic and biotic TCE dissolution fluxes. Experimental concentration gradients and their standard deviations were calculated as the slope of the TCE concentration profiles shown in Figure 2 and the standard error on the fitted slope respectively. The theoretical abiotic concentration gradient was calculated as the slope of equation (2). Steady state dissolution fluxes were calculated from the concentration gradients with Fick's law (equation (5)), their standard deviations were calculated with the standard deviation of the effective TCE diffusion coefficient and of the concentration gradients. Time averaged diffusion fluxes were calculated from the measured TCE dissolved out of the DNAPL (explained in the text).

This TCE flux can be calculated with Fick's law (equation (5)), adapted for porous media:

$$
J_{T C E}=-\left.\theta \cdot \xi \cdot D_{0} \cdot \frac{d c_{T C E, w}}{d z}\right|_{z=0}
$$

where $J_{T C E}$ is the TCE flux through the interface of the DNAPL and the sand layer, $\xi . D_{0}$ is the effective diffusion coefficient for TCE in the sand layer (calculated as explained above) and $\mathrm{dc}_{\mathrm{TCE}, \mathrm{w}} /\left.\mathrm{dz}\right|_{\mathrm{z}=0}$ is the pore water concentration gradient at the interface of the DNAPL and the sand layer. As the biotic TCE concentration profiles are linear in the lower part of the sand layer and the abiotic concentration profiles are linear throughout the sand layer (Figure 2), the concentration gradients were calculated as the slope of these curves (Table 1). In addition, a theoretical concentration gradient was calculated with the slope of equation (2), which was in excellent agreement with the experimentally determined values (Table 1 ). From equation (2) it is clear that in steady state the abiotic concentration gradient only depends on the length of the sand layer. With Fick's law, an actual dissolution flux is calculated, which is here the steady state dissolution flux. In addition, the diffusion-cell setup also allows calculating a time averaged dissolution flux, as the total amount of TCE which has dissolved from the DNAPL can be determined. This total amount of TCE dissolved is the sum of the chloroethene amount removed by refreshing the water layer $(47.7 \%$ and $31.5 \%$ of the total amount dissolved in respectively the abiotic and biotic diffusioncells), the amount of chloroethenes remaining in the sand layer, which was determined by integrating the pore water concentration profiles $(52.3 \%$ and $38.3 \%$ in the abiotic and biotic diffusion-cells respectively) and the cisDCE amount present in the DNAPL layer both in the aqueous solution and partitioned in the DNAPL phase $130.1 \%$ in the biotic diffusioncells). Time averaged dissolution fluxes were calculated by dividing the total amount of TCE dissolved by the diffusion-cell cross-section and the experimental duration (Table 1). In most diffusion-cells time averaged dissolution fluxes were somewhat higher than steady state dissolution fluxes, likely because of the higher dissolution flux during the initial transient stage. This demonstrates that the use of Fick's law is an easy and correct manner for calculating dissolution fluxes for the diffusion- 
cells. The calculated TCE concentration gradient at the DNAPL and sand layer interface and the steady state dissolution flux were a factor 2.4 (ratio of the biotic and abiotic means, standard deviation 0.2) higher in the biotic diffusion-cells compared to the abiotic diffusion-cells. This factor quantifies the bio-enhanced DNAPL dissolution in the biotic diffusion-cells.

\section{DISCUSSION}

The diffusion-cell presented in this study is a new bench-scale setup to quantify the bioenhanced dissolution of DNAPL. In this setup there is only diffusion with fixed boundary conditions and no flow, creating a system of low complexity, which processes can be easily described. For instance, measurement of the concentration gradient at the DNAPL interface precisely and reproducibly assessed the DNAPL dissolution flux (Table 1). In contrast, the complexity of flow-through setups does not allow an easy estimation of the DNAPL dissolution flux. In setups like 1-D columns and 2-D and 3-D tanks the difference in effluent composition between an abiotic and biotic replicate is used to calculate a dissolution enhancement factor (Amos et al., 2008, 2009; Sleep et al., 2006; Yang and McCarty, 2002). In our diffusion-cell a dissolution enhancement factor is calculated by comparing abiotic and biotic dissolution fluxes. The abiotic concentration gradient was also calculated with equation (2) (Table 1). As such, abiotic diffusioncells are strictly not required to quantify the bio-enhanced dissolution, but are necessary for determining the effective diffusion coefficient of TCE in other porous materials. In addition, the diffusion-cell setup allows measuring the conditions near the DNAPL. In this study both dechlorination and $\mathrm{pH}$ were characterized in relation to the distance of the DNAPL (Figure 2). In contrast, most flowthrough setups only measure effluent concentrations or quantify pore water concentrations at a coarse grid.

Our diffusion-cell simulates a simplified source zone. The DNAPL layer represents a pooled
DNAPL. The sand layer simulates a reactive noflow zone, while the water layer represents a fast flow, acting as a zero-sink for the dissolved chloroethenes and supplying electron donor. The diffusion-cell system includes many simplifications in comparison to real source zones. For instance, a complex DNAPL structure and a slow ground water flow throughout the source zone are expected in situ (Mayer and Hassanizadeh, 2005). However, our diffusioncell can contribute as a simple lab-scale setup in the investigation of unbiased bio-enhanced dissolution, before more realistic but complex systems are tested.

In this study bio-enhanced dissolution of TCE DNAPL was a factor $2.4 \pm 0.2$ above abiotic dissolution. This factor falls in the wide range of enhancement factors reported for PCE, which vary between 1.5 and 21 (Amos et al., 2009). Our enhancement factor is at the lower end of this range, maybe because of the stronger selfinhibition for TCE in comparison to PCE (degradation of TCE till $2.5 \mathrm{mM}$ while the saturation concentration is $8 \mathrm{mM}$, in comparison to degradation of PCE till saturation (1.8 mM) (Yang and McCarty, 2000)) - In the diffusion-cell setup, the abiotic dissolution flux only depends on the length of the sand layer (explained above), while the biotic dissolution flux rather depends on the effective TCE diffusion coefficient and the degradation kinetics of the dechlorinating culture. A longer sand layer, therefore, would reduce the abiotic dissolution flux and, as such, increase the dissolution enhancement. However, since electron donor is supplied at the top water layer, electron donor limitations are likely to arise in longer sand layers, which would decrease the biotic dissolution flux. Excluding limitations by adding sufficient electron donor to the top water layer, a constant biotic diffusive flux and an increased dissolution enhancement factor can be expected with increasing sand layer length. However, a limited bio-enhanced dissolution is interesting to investigate as in field conditions limitations are likely to occur. 
Amos et al. (2009) discussed that the mechanisms explaining the wide range of reported dissolution enhancements for PCE DNAPL are not well known. The diffusion-cell setup can be used to investigate which abiotic and biotic factors affect the bio-enhanced dissolution. Less permeable material in the central layer (lower effective diffusion coefficient) would steepen the biotic concentration gradient and, as such, increase the dissolution enhancement factor. In addition, both a better acclimatization to high chloroethene concentrations and a higher dechlorination rate would shift the position of the dechlorinating activity closer to the DNAPL. In contrast, electron donor limiting conditions and poor $\mathrm{pH}$ buffer capacities are expected to lower the bio-enhanced dissolution. Different cultures could be tested with the diffusion-cell setup to compare their ability to enhance the DNAPL dissolution. In addition, the setup could be used to test bioaugmentation, donor delivery and $\mathrm{pH}$ buffer addition strategies for source zones.

\section{CONCLUSION}

This paper shows that our three-layer diffusioncell is a simple and easy to handle bench-scale setup, which allows the quantification of the bio-enhanced dissolution of DNAPL and the measurement of the local conditions in the vicinity of the DNAPL. In biotic diffusion-cells dechlorination was located between 1.5 and $2.5 \mathrm{~cm}$ from the DNAPL. At smaller distances from the DNAPL, dechlorination was likely inhibited by TCE self-inhibition, while at distances from the DNAPL beyond $2.5 \mathrm{~cm}$ TCE was completely depleted. The DNAPL dissolution rate in the biotic cells was $2.4 \pm 0.2$ times enhanced compared to the abiotic diffusion-cells. This diffusion-cell setup can be used to investigate the effect of abiotic and biotic factors on the bio-enhanced dissolution.

\section{ACKNOWLEDGEMENTS}

This research was funded as a Ph.D. Fellowship of the Research Foundation - Flanders (FWO).

\section{REFERENCES}

Adamson, D.T., Lyon, D.Y., Hughes, J.B., 2004. Flux and product distribution during biological treatment of tetrachloroethene dense nonaqueous-phase liquid. Environ. Sci. Technol. 38, 2021-2028.

Adamson, D.T., McDade, J.M., Hughes, J.B., 2003. Inoculation of DNAPL source zone to initiate reductive dechlorination of PCE. Environ. Sci. Technol. 37, 2525-2533.

Amos, B.K., Christ, J.A., Abriola, L.M., Pennell, K.D., Loffler, F.E., 2007. Experimental evaluation and mathematical modeling of microbially enhanced tetrachloroethene (PCE) dissolution. Environ. Sci. Technol. 41, 963-970.

Amos, B.K., Suchomel, E.J., Pennell, K.D., Loffler, F.E., 2008. Microbial activity and distribution during enhanced contaminant dissolution from a NAPL source zone. Water Res. 42, 2963-2974.

Amos, B.K., Suchomel, E.J., Pennell, K.D., Loffler, F.E., 2009. Spatial and temporal distributions of Geobacter lovleyi and Dehalococcoides spp. during bioenhanced PCE-NAPL dissolution. Environ. Sci. Technol. 43, 1977-1985.

Barnes, R.J., Riba, O., Gardner, M.N., Singer, A.C., Jackman, S.A., Thompson, I.P., 2010. Inhibition of biological TCE and sulphate reduction in the presence of iron nanoparticles. Chemosphere 80, 554-562.

Carr, C.S., Garg, S., Hughes, J.B., 2000. Effect of dechlorinating bacteria on the longevity and composition of PCE-containing nonaqueous phase liquids under equilibrium dissolution conditions. Environ. Sci. Technol. 34, 10881094.

Cope, N., Hughes, J.B., 2001. Biologicallyenhanced removal of PCE from NAPL source zones. Environ. Sci. Technol. 35, 2014-2021.

Crank, J., 1986. The Mathematics of Diffusion. Clarendon, Oxford UK.

Da Silva, M.L.B., Daprato, R.C., Gomez, D.E., Hughes, J.B., Ward, C.H., Alvarez, P.J.J., 2006. Comparison of bioaugmentation and biostimulation for the enhancement of dense 
nonaqueous phase liquid source zone bioremediation. Water Environ. Res. 78, 2456-2465.

Duhamel, M., Wehr, S.D., Yu, L., Rizvi, H., Seepersad, D., Dworatzek, S., Cox, E.E., Edwards, E.A., 2002. Comparison of anaerobic dechlorinating enrichment cultures maintained on tetrachloroethene, trichloroethene, cis-dichloroethene and vinyl chloride. Water Res. 36, 4193-4202.

Fredrickson, J.K., Zachara, J.M., Kennedy, D.W., Dong, H.L., Onstott, T.C., Hinman, N.W., Li, S.M., 1998. Biogenic iron mineralization accompanying the dissimilatory reduction of hydrous ferric oxide by a groundwater bacterium. Geochim. Cosmochim. Acta 62, 3239-3257.

Glover, K.C., Munakata-Marr, J., Illangasekare, T.H., 2007. Biologically enhanced mass transfer of tetrachloroethene from DNAPL in source zones: Experimental evaluation and influence of pool morphology. Environ. Sci. Technol. 41, 1384-1389.

Gulliver, J.S., 2007. Introduction to Chemical Transport in the Environment. Cambridge University Press, New York.

Haest, P.J., Philips, J., Springael, D., Smolders, E., 2011. The reactive transport of trichloroethene is influenced by residence time and microbial numbers. J. Contam. Hydrol. 119, 89-98.

Haest, P.J., Springael, D., Smolders, E., 2010. Dechlorination kinetics of TCE at toxic TCE concentrations: Assessment of different models. Water Res. 44, 331-339.

Jury, W., Horton, R., 2004. Soil Physics. John Wiley \& Sons, Hoboken New Jersey USA.

Mayer, A., Hassanizadeh, S.M., 2005. Soil and Groundwater Contamination: Nonaqueous Phase Liquids - Principles and Observations. American Geophysical Union, Washington DC USA.

McCarty, P.L., Chu, M.Y., Kitanidis, P.K., 2007. Electron donor and $\mathrm{pH}$ relationships for biologically enhanced dissolution of chlorinated solvent DNAPL in groundwater. Eur. J. Soil Biol. 43, 276-282.
McCormick, M.L., Jung, P.T., Van Groos, P.G.K., Hayes, K.F., Adriaens, P., Petrovskis, E., Skubal, K.L., 2002. Assessing biotic and abiotic contributions to chlorinated solvent transformation in iron-reducing and sulphidogenic environments. In: Thornton, S.F., Oswald, S.E. (Eds.). Groundwater Quality: Natural and Enhanced Restoration of Groundwater Pollution. Int Assoc Hydrological Sciences, Wallingford, pp. 119125.

Moldrup, P., Olesen, T., Gamst, J., Schjonning, P., Yamaguchi, T., Rolston, D.E., 2000. Predicting the gas diffusion coefficient in repacked soil: Water-induced linear reduction model. Soil Sci. Soc. Am. J. 64, 1588-1594.

Schaefer, C.E., Towne, R.M., Vainberg, S., McCray, J.E., Steffan, R.J., 2010. Bioaugmentation for treatment of dense nonaqueous phase liquid in fractured sandstone blocks. Environ. Sci. Technol. 44, 4958-4964.

Sleep, B.E., Seepersad, D.J., Mo, K., Heidorn, C.M., Hrapovic, L., Morrill, P.L., McMaster, M.L., Hood, E.D., LeBron, C., Lollar, B.S., Major, D.W., Edwards, E.A., 2006. Biological enhancement of tetrachloroethene dissolution and associated microbial community changes. Environ. Sci. Technol. 40, 3623-3633.

Yang, Y.R., McCarty, P.L., 2000. Biologically enhanced dissolution of tetrachloroethene DNAPL. Environ. Sci. Technol. 34, 2979-2984.

Yang, Y.R., McCarty, P.L., 2002. Comparison between donor substrates for biologically enhanced tetrachloroethene DNAPL dissolution. Environ. Sci. Technol. 36, 34003404. 